\title{
SEVERINO BOECIO [Ser y conocer - antología de textos]*
}

Tradução de

Antonio Domingo Tursi**

\section{Comentario a la Isagogé de Porfirio ${ }^{1}$}

\section{[Texto de Porfirio]}

[82a] "Ahora bien, respecto de los géneros y las especies si es que subsisten o si están colocados solo en pensamientos desnudos, o si, en tanto subsistentes, son corpóreos o incorpóreos, y si están separados de las cosas sensibles o colocados en las cosas sensibles, sobre [82b] estas posiciones, empero, rehusaré hablar. Pues una empresa de este tipo es profundísima y exige de un examen más amplio."

\section{[1. Replanteo de Boecio]}

Cuestiones más profundas - dice [Porfirio] - paso por alto a fin de no perturbar, al presentarlas intempestivamente al ánimo del lector, sus fundamentos y principios. Pero para no obrar negligentemente al punto que nada, con excepción de lo que el propio lector llegase a manifestar, se juzge oculto, aquello mismo, cuya con-

- Este pasaje de Boecio, planeado como un excurso en su comentario a la obrita de Porfino a fin de no postergar un problema que el discipulo de Plotino alude, es uno de los textos más importantes en la historia del pensamiento, no sólo por ser el punto de partida del llamado "problema de los universales", sino también, y fundamentalmente, por consistir en un análisis agudo y sagaz del conocimiento y del tipo de existencia atribuible a los géneros y especies.

La traducción que aqui ofrecemos intenta seguir puntualmente el texto latino, del cual hay dos ediciones modernas, la de J. P. Migne en el volumen 64 de la Patrologia, Series latina, París, 1882; y la de S. Brandt, Boethii In Isagogen Porphyrii commenta, Lipsiae 1906, reproducida en el volumen 48 del C.S.E.L. Respecto de nuestra versión la hemos dividido en parágrafos titulados, y encerrado entre corchetes los términos supuestos en el original latino a fin de conseguir una lectura más ágil. Finalmente, queremos destacar dos traducciones, una la del término intellectus que Boecio utiliza con dos sentidos diferentes, de un lado, como la facultad de conocer, y, de otro, como el producto de la facultad de conocer. En cada caso hemos creído respetar el sentido. La otra, que hemos traducido res subiecta por "cosa aprehendida", entendiendo por tal la imagen sensible, producto de los sentidos.

* Universidad de Buenos Aires

1 (PL. 64, 82a-86a)

\begin{tabular}{|l|l|l|l|l|l|}
\hline VERITAS & Porto Alegre & v. 41 & $\mathrm{n}^{2} 163$ & Setembro 1996 & p. 541-552 \\
\hline
\end{tabular}


bre ello lo más mínimo de oscuridad, exponiendo profundamente al lector todo asunto dificultoso y, así, robustecido por el saber, conozca qué puede ser inquirido con derecho.

Hay, entonces, cuestiones que Porfirio decide callar, las cuales son muy útiles y peculiares y que tratadas ciertamente por sabios varones, no han sido resueltas por ninguno. De entre ellas la primera es ésta: todo lo que el espíritu intelige radica en que o bien concibe con el intelecto y ordena, para sí mismo, con la razón, aquello que está constituido en [82c] la naturaleza de las cosas, o bien se representa con la libre imaginación aquello que no existe [en la realidad].

En consecuencia, se debe indagar sobre el conocimiento del género y de los restantes [términos] de este tipo, si inteligimos las especies y los géneros como [inteligimos] aquellas cosas que existen y a partir de las cuales aprehendemos lo inteligible, o bien si nosotros mismos nos las figuramos cuando formamos con la imaginación cosas vanas que no existen.

Mas si se diera por descontado que [los géneros y las especies] existen [en la realidad] y dijéramos que el entendimiento los concibe a partir de las cosas que existen, entonces otra cuestión mayor y más difícil se plantea. Efectivamente, una suma dificultad se presenta para discernir e inteligir la naturaleza del género mismo. Pues, como todo lo que existe es necesario que sea o corpóreo o incorpóreo, convendrá que el género y la especie estén en uno de esos. ¿Cómo será, entonces, eso que [82d] se llama género, corpóreo o incorpóreo? No se pretende conocer diligentemente qué es [el género], sino dilucidar en cuál de ésos debe estar colocado. Y aunque no fuera solucionada esta cuestión, se puede disipar toda duda. En efecto, supóngase que se asienta y delimita su conocimiento, si se dijera que el género y las especies son incorporales. Pregunto ahora si subsisten en los cuerpos mismos, o si parecen existir como incorpóreos, más allá de los cuerpos subsistentes.

Hay, ciertamente, dos formas de incorpóreos: por una parte, los que pueden existir más allá de los cuerpos y que, separados de los cuerpos, perduran en su integridad, como [por ejemplo] Dios, la mente, el alma. Por otra, los que, aunque sean incorpóreos, sin embargo no pueden existir más allá de los cuerpos, como [por ejemplo] la línea, la superficie, el número y las cualidades [83a] singulares; las cuales, aunque las llamamos incorpóreas porque no se extienden en tres dimensiones, con todo existen en los cuerpos al punto que no puedan ser arrancadas o separadas de ellos; pues si fueran separadas de los cuerpos, no podrían existir de ningún modo.

A pesar de ser estas cuestiones un tema arduo, y que el propio Porfirio fue renuente al respecto, sin embargo intentaré resolverlas para no dejar ansioso el ánimo del lector, y no consumir tiempo y fatiga en cuestiones que están más allá del orden del trabajo emprendido.

En primer lugar, expondré unas pocas cosas sobre las dudas de la cuestión, y después intentaré resolver y explicar el nudo mismo del problema. 


\section{[2.1. Aporias a que conduce el texto de Porfirio]}

Los géneros y las especies o bien existen y subsisten, o bien son formados por el entendimiento y el solo pensamiento. Pero los géneros y las especies no pueden existir. Y ello se comprende a partir de lo siguiente.

\section{[2.1.1. El universal como uno]}

En efecto, todo lo que es, $[\mathbf{8 3 b}]$ al mismo tiempo, común a muchos, no podría ser en sí uno. Pues lo que es común es propio de muchos; sobretodo cuando una y la misma cosa está toda, al mismo tiempo, en muchos. Así pues, cuantasquiera sean las especies, en todas el género es uno. No porque cada una de las especies se deriva del [género], como si fuera [cada especie] una parte de él, sino porque cada una [de las especies] posee, al mismo tiempo, todo el género. Por ello sucede que todo el género, colocado al mismo tiempo en todos los individuos, no podría ser uno. Ni tampoco es posible que [el género], estando todo al mismo tiempo en muchos, sea en sí mismo uno en número. Porque si así fuera, no podría ser un género único; en rigor, no sería nada. En efecto, todo lo que es, es justamente porque es uno; y lo mismo conviene decir de la especie.

Porque si el género, como la especie, fuera múltiple y no uno en número, no podría haber un género último, sino que tendría [que haber] colocado sobre él otro [83c]género que englobara aquella multiplicidad bajo la sola acepción de su nombre; como [por ejemplo] los múltiples animales que, teniendo algo similar, con todo no son la misma cosa, y por ello requieren géneros propios. Y porque el género que está en todos y que por ello es múltiple, guarda una similitud respecto de ellos, en cuanto que es género, no es, sin embargo, uno, ya que está en muchos.

Así entonces, debe buscarse otro género de ese género, y, aunque se lo hallara, por la misma razón que se mencionó antes, debería, a su vez, buscarse un tercer género y, así, parecería necesario que la razón procediera hasta el infinito, si es que no encuentra ningún término en su tarea.

\section{[2.1.2. El universal como común]}

$\mathrm{Y}$ aunque haya un cierto género, uno en número, bien podría no ser común a muchos. Pues una cosa si es común, lo es o bien respecto de sus partes y ya no es toda común, sino con referencia a sus partes, [83d] con propiedad, a sus individuos; o bien si, para que sea común, viene dada según la costumbre de las cosas adquiridas a través del tiempo, como [por ejemplo] un pozo, una fuente, como es común un siervo o un caballo; o bien si es, al mismo tiempo, común a todas las cosas, pero no en el sentido de la sustancia respecto de aquellas cosas a las que es común, sino como es el teatro o algún espetáculo que es común a todos los espectadores. Pero el género no puede ser común a las especies según ninguno de los [tres] modos aludidos. Fues [el género] debe ser común a tal punto que no sólo esté todo en los individuos, sino también al mismo tiempo, y además pueda [el género] establecer.y conformar, respecto de aquellas cosas a las que es común, una sustancia. 
Así pues, si [el género] no es uno, porque es común; ni múltiple, porque [84a] [en tal caso] habria que buscar otro género [que englobe] aquella multitud, parecerá que el género no existe en absoluto; y lo mismo podría establecerse respecto de los restantes [términos universales].

\section{[2.2. El universal como formación del pensamiento]}

\section{[2.2.1. El universal coincide con la cosa existente]}

Pero si sólo por medio de las operaciones intelectuales se aprehenden los géneros, las especies y los restantes [términos], en tanto todo lo inteligido surge a partir de la cosa aprehendida, sea que esa cosa exista [en la realidad], sea que no exista [en la realidad], vano es [el conocimiento] que es tomado de una cosa aprehendida que no existe [en la realidad]; pues no puede surgir conocimiento de una cosa aprehendida no existente.

Si el conocimiento del género, de la especie y de los restantes [términos] viene a partir de la cosa aprehendida, al punto que la cosa que es inteligida existe [en la realidad], entonces no está [género y especie] sólo colocados en el entendimiento, también están constituidos en la verdad de las cosas [existentes].

\section{[2.2.2. El universal no coincide con la cosa existente]}

A su vez, se debe buscar cuál es la naturaleza de estos [términos]; justamente lo mismo que planteaba la cuestión anterior. Pues, si el conocimiento del género y de los restantes [términos] es tomado de la cosa, en tanto que se tiene como aprehendida, vano [también] es necesario [84b] que sea ese conocimiento que es tomado de la cosa, en tanto no existente; pues es falso aquello que es conocido de manera diferente a como la cosa existe. Por otra parte, si el género y las especies no existen, ni, cuando son conocidos, es verdadero su conocimiento, no hay duda de que toda preocupación de especular sobre estos cinco predicables debe deponerse, puesto que no se inquiere sobre la cosa que existe, ni sobre [la cosa] de la cual podría conocerse o extraerse algo verdadero.

\section{[3. Solución de las dudas]}

\section{[3.1. Facultades del conocimiento]}

Esta es, hasta ahora, la cuestión sobre los predicables que nosotros, de acuerdo con Alejandro [de Afrodisia], por medio del siguiente razonamiento intentaremos resolver.

En efecto, afirmamos que no es necesario que todo conocimiento, que sea a partir de la cosa aprehendida, en tanto no se tenga como existente, se presenta falso o libre. Pues en esos conocimientos sólo hay una falsa opinión, que surge por conjunción, y no [hay], más bien, conocimiento. [84c] De hecho, si alguien compone y une con el entendimiento aquello que la naturaleza no tolera que esté unido, nadie ignora que ello es falso. Es como si alguien quisiera unir un caballo con un hombre gracias a la imaginación, y construyera un centauro. Ello si se hace por división y abstracción, no es una cosa real existente, sino otra propia del entendimiento. Sin embargo, ese conocimiento no es del todo falso. Pues hay muchas co- 
sas que tienen su ser en otro [ser], de las cuales o bien algunas no pueden ser separadas en absoluto, o bien otras, si estuvieran separadas, no subsisten por ninguna razón.

Y para que ello se nos haga manifiesto, vaya un ejemplo recurrente: la línea es algo en el cuerpo, y eso que es se lo debe al cuerpo; o sea que su ser está retenido en el cuerpo. Esto nos enseña lo siguiente; si la línea estuviera separada del cuerpo, no subsistiría; pues, ¿quién, alguna vez, aprehendió con algún sentido una línea separada de un cuerpo? [84d] Pero el espíritu cuando concibe en sí, a partir de los sentidos, las cosas que están confundidas y mezcladas en los cuerpos, las distingue con su propia facultad y pensamiento. Pues a todas estas cosas incorpóreas que tienen su ser en el cuerpo, el sentido nos las otorga con los mismos cuerpos; mas el espíritu, que tiene la potestad de componer las cosas desunidas y disolver las cosas compuestas que son otorgadas e los sentidos en forma confusa y conjuntas con los cuerpos, a tal punto las distingue que no sólo las ve, sino también especula sobre su naturaleza incorpórea por sí y sin los cuerpos en los cuales estaba concreta. De hecho, son diversas las propiedades incorpóreas mezcladas en los cuerpos, y separables del cuerpo.

Entonces, los géneros y las especies y los restantes [términos] o bien se encuentran en las cosas incorpóreas, o bien en aquellas que son cuerpos. Si el espíritu las halla en las incorpóreas, [85a] ahi mismo ya tiene el conocimiento incorpóreo del género. Pero si detecta los géneros y las especies en las cosas corporales, quita, como es su costumbre, de los cuerpos la naturaleza de las cosas incorpóreas, y la contempla simple y pura, como de hecho es la forma en sí misma. Así, una vez que el espíritu percibe esas [formas o naturalezas incorpóreas] mezcladas en los cuerpos, separándolas [en tanto que] incorpóreas, especula y considera.

Nadie, por lo tanto, nos diga que pensamos como falsa la línea, ya que la concebimos con la mente como si estuviera más allá del cuerpo, aunque no podría existir más allá del cuerpo.

En efecto, no todo conocimiento que se concibe a partir de las cosas aprehendidas, diferentes de las cosas mismas que existen, debe ser considerado falso, sino - como se dijo antes - sólo aquel que se lleva a cabo por composición es falso, como cuando uniendo hombre y caballo [alguien] cree que el centauro existe [en la realidad]. Pero aquel que se lleve a cabo por división y abstracción y asumisiones a partir de las cosas que existen, [85b] de ningún modo es falso, antes bien es el único conocimiento que puede encontrar con propiedad aquello que es verdadero.

En consecuencia, existen las cosas [incorpóreas] en los cuerpos y en las cosas sensibles, pero se inteligen más allá de lo sensible, en tanto se puede percebir su naturaleza y comprender su propiedad.

\section{[3.2. Naturaleza y definición de los universales]}

Al respecto, cuando los géneros y las especies son pensados, es porque se colige una similitud a partir de los individuos existentes, como a partir de los hombres individuales [por ejemplo] se colige una similitud de humanidad entre ellos. Dicha similitud, una vez pensada por el espíritu y corroborada fehacientemente, se convierte en especie. De las diversas especies, a su vez, se considera una similitud. Esta, que no puede existir sino en las mismas especies y en sus [respectivos] 
individuos, produce el género. Así pues, [los géneros] estan en los individuos. Con todo, son pensados como universales. Y la especie [85c] no debe ser considerada otra cosa, sino un pensamiento colegido a partir de la similitud substancial de individuos disímiles en número. Y el género, por su parte, como un pensamiento colegido a partir de la similitud de las especies.

Ahora bien, esta similitud, cuando está en los individuos, es sensible y permanece en los individuos; cuando es inteligida, se convierte en universal. En consecuencia, [géneros y especies] subsisten en las cosas sensibles, pero se inteligen más allá de los cuerpos.

Pues, no hay obstáculo para que dos cosas, en una misma cosa aprehendida, no sean distintas por razón, como [por ejemplo] la línea cóncava y la convexa. Estas aunque se determinan por distintas definiciones y distinto sea su conocimiento, con todo siempre se encuentran en la misma cosa aprehendida. Pues la línea cóncava es la misma que la convexa. Así también puede decirse lo mismo respecto de los géneros y las especies. Esto es, una misma cosa aprehendida tiene regularidad y [a la vez] universalidad. Es universal cuando es pensada. Es singular cuando es percibida en las cosas que existen.

\section{[4. Respuesta puntual al texto de Porfirio y una alusión histórica]}

Así pues, habiendo delimitado esto, toda la cuestión, según creo, queda resuelta. Pues los géneros y las especies subsisten de un modo, pero [86a] son inteligidos de otro modo. Son incorpóreos, pero junto a las cosas sensibles subsisten como insensibles, mas se inteligen más allá de los cuerpos, como subsistentes por sí mismos, esto es, no teniendo su ser en otro [ser].

Con todo, Platón piensa que no sólo los géneros y las especies y los restantes [términos] se inteligen como universales, sino también existen y subsisten más allá y como causa de los cuerpos. Aristóteles, por su parte, piensa que son inteligidos como incorpóreos universales, pero que subsisten en lo sensible. Yo no quiero decidir cuál opinión de ambas es la apropiada, pues es tema para una filosofía más profunda. Al respecto hemos seguido con aplicación la opinión de Aristóteles, no porque la aprobamos en grado sumo, sino porque de este libro que versa sobre los predicamentos es Aristóteles su autor.

\section{Contra Eutiques y Nestorio ${ }^{2}$}

\section{I}

Naturaleza puede decirse o bien sólo de los cuerpos o bien sólo de las sustancias, o sea de los seres corpóreos e incorpóreos, o bien de todas las cosas que de algún modo se dice que existen. Entonces, como naturaleza puede decirse de tres modos, debe definirse sin duda de tres modos. Pues, si se quiere que naturaleza se diga de todas las cosas, se dará una definición tal que pueda incluir todas las cosas que existen. En consecuencia, será de este modo: naturaleza es propia de las cosas que, en cuanto existen, pueden ser de algún modo captadas con el intelecto. Pues

2 PL 64, 1341b-1345b 
en esta definición se definen no sólo los accidentes, sino también las sustancias; en efecto, todas éstas, accidentes y sustancias, pueden ser captadas con el intelecto. Se agrega "de algún modo", porque Dios y la materia no pueden ser inteligidas con un intelecto íntegro y perfecto, pero, sin embargo, son captados de algún modo por la privación de las restantes cosas. Y al respecto agregamos "las cosas en cuanto existen", porque inclusive la misma nada significa algo pero no una naturaleza. En efecto, significa no que algo exista, sino más bien el no existir, mas toda naturaleza existe. Y, ciertamente, si quiere decirse naturaleza de todas las cosas, sea ésa la definición de naturaleza que propusimos antes. $\mathrm{Si}$, en cambio, se dice naturaleza sólo de las sustancias, porque todas las sustancias son o bien corpóreas o bien incorpóreas, daremos una definición de naturaleza para significar sustancias de este modo: naturaleza es o bien lo que puede hacer o bien lo que puede padecer. Padecer y hacer, ciertamente, como todas las cosas corpóreas y el alma de las corpóreas; pues ésta en el cuerpo y a partir del cuerpo no sólo hace sino también padece. Mas hacer, solamente Dios y los restantes seres divinos. Así pues tiene inclusive una definición de esa significación de naturaleza que solamente se aplica a las sustancias. Aquí resultó también la definición de sustancia. Pues si el nombre de naturaleza muestra la sustancia, cuando hemos descripto la naturaleza, también se ha concedido la descripción de sustancia. Y si el nombre de naturaleza, dejadas de lado las sustancias incorpóreas, se reduce a tal punto a las corporales, que sólo las sustancias corporales parezcan tener una naturaleza, como Aristóteles y los restantes seguidores no sólo de su filosofía, sino también de muchas otras piensan, definámosla como éstos que impusieron que la naturaleza no existe sino en los cuerpos. Su definición es pues de este modo: naturaleza es el principio del movimiento por sí, no por accidente. Respecto de que digo "principio de movimiento", esto es porque todo cuerpo posee su propio movimiento, como el fuego hacia arri$\mathrm{ba}$, la tierra hacia abajo. Igualmente respecto de que propuse que la naturaleza es "principio de movimiento por si" y no "por accidente", tal es porque es necesario que una cama de madera vaya hacia abajo, pero no vaya por accidente hacia abajo. En efecto, porque la cama existe, porque existe la tierra, cae por su peso y gravedad. En efecto, no porque la cama existe, cae hacia abajo, sino porque la tierra existe, o sea porque atañe a la tierra que la cama exista; de donde sucede que digamos que la madera existe por naturaleza, la cama en cambio por arte. Existe, con todo, otra significación de naturaleza por la cual decimos que es distinta la naturaleza del oro y de la plata, deseando demostrar al respecto la propiedad de las cosas, esta significación de naturaleza se podría definir de este modo: naturaleza es la diferencia específica que da forma a cualquier cosa. En consecuencia, como naturaleza no sólo se dice sino también se define de tantos modos, así tanto los católicos cuanto Nestorio establecen que en Cristo existen dos naturalezas según la última definición; y que, en efecto, no convienen las mismas diferencias a Dios y al hombre.

\section{II}

Pero respecto de persona es posible sobremanera dudar de si alguna definición se le pudiera adaptar. En efecto, si toda naturaleza tiene una persona, un nudo in- 
disoluble es cuál pueda ser la diferencia entre naturaleza y persona; o si no se iguala persona a naturaleza, sino que debajo del término y del lugar de naturaleza la persona subsiste, es difícil de decir a qué naturalezas se extiende la persona, o sea a qué naturalezas convenga tener una persona, y qué naturalezas se separan del término de persona. Mas, ciertamente, esto es manifiesto, que la naturaleza es sustrato de la persona, y que la persona no puede ser predicada independientemente de la naturaleza. Entonces, se debe investigar éstas en este sentido.

Porque la persona no puede existir independientemente de la naturaleza y porque algunas naturalezas son sustancias, otras accidentes y vemos que la persona no puede estar constituida en los accidentes (¿quién, en efecto, podría decir que exista alguna persona de la blancura o de la negrura o de la magnitud?), resta, por lo tanto, que convenga que la persona se diga en las sustancias. Pero algunas de las sustancias son corpóreas, otras incorpóreas; y algunas de las corpóreas son vivientes, otras no; algunas de las vivientes son sensibles, otras no; algunas de las sensibles son racionales, otras irracionales. Igualmente algunas de las incorpóreas son racionales, otras no, como la vida de los animales; mas una de las racionales es inmutable e impasible por naturaleza, Dios; otra, por creación, mutable y pasible, a no ser que por la gracia de la sustancia impasible llege a transformarse en la firmeza de la impasibilidad, como la de los ángeles y la del espíritu. De todas estas cosas es manifiesto que ni puede decirse persona en los cuerpos no vivientes (ninguno, en efecto, dice que una de las piedras es una persona), ni a la vez puede decirse persona de los vivientes que carecen de sensibilidad (ninguna persona, en efecto, es un árbol), ni puede decirse persona de la sustancia que está privada de intelecto y razón (en efecto, no hay persona del caballo o del buey y de los restantes animales que, mudos y sin razón, pasan la vida con los solos sentidos), mas decimos que hay persona del hombre, lo decimos de Dios, lo decimos del ángel. Inclusive algunas de las sustancias son universales, otras particulares. Universales son las que se predican de los individuos, como hombre, animal, piedra, leño y las restantes de este modo que son o bien géneros o bien especies; pues no sólo hombre se dice de los hombres individuales, sino también animal se dice de los animales individuales y la piedra y el leño se dicen de las piedras y leños individuales. En cambio particulares son las que no se predican de otras como Cicerón, Platón, esta piedra a partir de la cual esta estatua de Aquiles se ha hecho, este leño a partir del cual esta mesa se ha fabricado. Mas en todos estos persona nunca puede decirse en los universales, sino sólo en los singulares y en los individuos; en efecto, ninguna persona hay del animal o del hombre en general, sino que personas individuales se designan ya de Cicerón ya de Platón ya de los individuos singulares.

\section{III}

Entonces, si la persona está sólo en las sustancias y en estas racionales, y si sustancia es toda naturaleza y no reside en los universales sino en los individuoss, la definición descubierta de persona es: sustancia individual de naturaleza capaz de razón. Pero nosotros con esta definición determinamos la que los griegos llaman hypóstasis. En efecto, el nombre de persona parece extraído de otro lado, a saber, 
de estas máscaras que representaban a los personajes que participaban en las comedias y tragedias. Persona, por su parte, viene de personare, con la penúltima silaba larga. Y si se acentuara la antepenúltima, se verá manifiestamente que viene de sonus; efectivamente de sonus, porque es necesario que el sonido se vuelva mayor por la concavidad misma de la máscara. Los griegos tambén llaman a estas máscaras de prósopa, por esto que se colocan en la cara y a los ojos del espectador ocultan la expresión: pará toū prós toús ōpas títhesthai. Porque, cubiertos con máscaras, los actores representaban individuos, personajes que participaban en la tragedia o la comedia, como se dijo, o sea Hécuba, Medea, Simón o Cremetes, e igualmente los restantes personajes, de quienes era seguro el reconocimiento por su fisonomía, los latinos utilizaron persona y los griegos prósopa. Y, mucho más significativo, ellos llamaron a la subsistencia individual de naturaleza capaz de razón con el nombre de hypóstasis; nosotros, en cambio, por la falta de voces significativas retuvimos la designación tradicional, llamando persona a la que ellos dicen hypóstasis; la Grecia, más experta en palabras, llama hypóstasis a la subsistencia individual. $Y$, por utilizar una oración griega en cuestiones que, discutidas por los griegos, ha sido traducida en versión latina: hai ousíai en men tois kathólou einai dynantai en dé toís atómois kai katá méros mónois hyphístantai, esto es: las esencias pueden existir en los universales, mas sólo en los individuales y en los particulares permanecen. En efecto, la intelección de las cosas universales es sacada de los particulares. Por ello, como las subsistencias mismas existen en los universales, mas toman su sustancia en los particulares, con derecho llamaron hypostáseis a las subsistencias que permanecen en forma particular. Y no le parecerá al que considere la cosa más valiosa y sutilmente que la subsistencia es lo mismo que la sustancia.

Pues los griegos llaman ousíosis o ousiōsthai, nosotros lo denominamos subsistencia o subsistir; lo que ellos hypóstasis o hyphistasthai, nosotros lo interpretamos como sustancia o permanecer. Subsiste, en efecto, lo que no necesita de accidentes para poder existir. Permanece, empero, lo que suministra a los otros accidentes un cierto sustrato para que puedan existir; bajo ellos, en efecto, está, en tanto es sustrato para los accidentes. Entonces, los géneros o las especies sólo subsisten; en efecto, los accidentes no atañen a los géneros o las especies. Mas los individuos no sólo subsisten sino también permanecen, pues ellos no necesitan de accidentes para existir; en efecto, están ya conformados por sus propiedades y por sus diferencias especificas, y suministran a los accidentes el hecho de que puedan existir, en tanto son, de hecho, sustratos. Por ello einai y ousiōsthai se inteligen como existir y subsistir, en cambio hyphístasthai como permanecer. En efecto, no es pobre la Grecia en palabras, como Cicerón alude, sino que toma a esencia, subsistencia, sustancia, persona, con otros nombres, llamando a la esencia ousía, a la subsistencia ousíosis, a la sustancia hypóstasis, a la persona prósopon. Asi pues los griegos llamaron hypostáseis a las sustancias individuales, porque existen a la base de las restantes, o sea como si se dijera que están puestas debajo y son sustratos para cualesquiera accidentes; y por ello nosotros también las llamamos sustancias como si se dijera subpuestas, a las que ellos llaman hypostáseis, y como que también llaman prósopa a las mismas sustancias, nosotros podemos inclusive llamarlas personas. Así pues ousía es igual que esencia, lo mismo ousíosis que subsistencia, 
lo mismo hypóstasis que sustancia, lo mismo prósopon que persona. Por ello el griego no diría hypóstasis de animales irracionales, como nosotros acerca de los mismos predicamos el nombre de sustancia; la razón es ésta: porque este nombre está aplicado a los mejores, a tal punto que de alguna manera lo que es más excelente, aunque no por medio de una descripción de la naturaleza según lo que es hyphistasthai y permanecer, más bien con los términos de hypóstasis o sustancia es discernido.

Entonces, es propia del hombre ciertamente una esencia, o sea una ousía, y una subsistencia, o sea una ousíosis, y una hypóstasis, o sea una sustancia, y una prósopon, o sea una persona; una ousía, una esencia, porque es algo; una ousíosis, una subsistencia, porque en ningún sujeto está; una hypóstasis, una sustancia, porque está por debajo de las restantes realidades que no son subsistencias, o sea no son ousíoseis; es una prósopon, una persona, porque es un individuo capaz de razón. Dios también es ousía, esencia; existe de hecho y es él mismo máximamente por quien surge el existir de todas las cosas. Es ousíosis, o sea subsistencia (en efecto, subsiste no necesitando de nada), e hyphístasthai, permanece efectivamente. De onde también decimos que una es la ousía o ousíosis, o sea la esencia o la subsistencia de la deidad, pero tres son las hypostáseis, o sea tres las sustancias. Y ciertamente, de acuerdo con este modo, se ha dicho que una es la esencia de la trinidad, tres las sustancias y tres las personas. En efecto, a no ser que el uso de hablar eclesiástico excluyera que tres son las sustancias en Dios, parecería por ello que la sustancia se dice de Dios, no porque él podría estar supuesto como sustrato de las restantes cosas, sino porque él, como está antes que todas las cosas, así inclusive está por debajo como principio de las cosas, en cuanto les suministra a todas el ousiōsthai o subsistir.

\section{Sobre la Trinidad ${ }^{3}$}

Ya que son tres las partes especulativas de la filosofía: la natural, sobre las cosas en movimiento, no abstractas, anypexairetos (inseparables). (En efecto, ésta considera las formas de los cuerpos en la materia, las cuales no pueden efectivamente separarse de los cuerpos que están en movimiento, como la tierra es llevada hacia abajo y el fuego hacia arriba; y la forma unida a la materia tiene movimiento); la matemática, sobre las cosas sin movimiento, no abstractas (pues, ésta especula sobre las formas de los cuerpos sin materia, y por elio sin movimiento; estas formas, existiendo en la materia, no pueden separarse de los cuerpos); y la teologia, sobre las cosas sin movimiento, abstractas y separables (de hecho, la sustancia de Dios carece de materia y de movimiento), en consecuencia convendrá trabajar en la natural en forma racionable; en la matemática, disciplinable, y en la divina, intelectualmente, y no dejarse llever hacia las imaginaciones, sino más bien inspeccionar la forma misma que es verdadera forma y no imagen, y que es el ser mismo y de la cual deriva el ser. Pues todo ser deriva de la forma. En efecto, no se dice que una estatua sea la reproducción de un animal por su bronce, que es su materia, sino por su forma que está impresa en él; y el bronce mismo no se dice tal

3 PL 64, 1250a-1251a 
por la tierra que es su materia, sino por la figura del bronce. Incluso la tierra misma no se dice tal por la materia informe, sino por la sequedad y la gravedad que son lo propio de su forma. Entonces, nada se dice que es según la materia, sino según su propia forma. Pero la sustancia divina es forma sin materia y por ello es algo único y es aquello que es. Pues las restantes cosas no son aquello que son. En efecto, cada cosa tiene su ser a partir de aquellas cosas de las cuales es, o sea de sus partes, y es esto o aquello, o sea sus partes unidas, pero no esto o aquello en forma singular, por ejemplo, ya que el hombre terreno esta constituido de alma y cuerpo, es cuerpo y alma, no ya cuerpo ya separadamente alma; por lo tanto no es aquello que es. Mas, lo que no es formado de esto y aquello, sino sólo es esto, ello es en verdad aquello que es; y es bello y fuerte en grado sumo ya que no depende de nada. Además, esto es en verdad algo único en el cual no hay ningún número, ni otra cosa es ello, a excepción de aquello que es. Y no puede llegar a ser sujeto, pues es forma, y las formas no pueden llegar a ser sujetos. Mas las restantes formas son sujetos para los accidentes, como la humanidad, que no recibe los accidentes por lo que ella misma es, sino porque la materia le está sujeta; pues en tanto la materia sujeta a la humanidad reciba algún accidente, parece que lo recibiera la humanidad misma. En cambio, la forma que es sin materia no podria ser sujeto ni tampoco adherir a la materia, pues no sería forma, sino imagen. En efecto, las formas que están en la materia y que constituyen un cuerpo son derivadas de esas formas que están más allá de la materia. Abusamos, pues, al llamar formas a las otras que están en los cuerpos, en tanto que son imágenes. En efecto, son asimiladas a esas formas que no están constituidas en una materia. En consecuencia, en Dios no hay diversidad, no hay pluralidad a partir de la diversidad, no hay multiplicidad a partir de los accidentes, y por ello tampoco número.

\section{La consolación de Filosofía, V, $4^{4}$}

Todo lo que se conoce es aprehendido no según su propia fuerza, sino más bien según la facultad de los que conocen. Para esclarecer esto, valga con un breve ejemplo: a la misma redondez de un cuerpo, de una manera la conoce la vista; de otra el tacto. Aquélla, manteniéndose alejada, percibe a la vez el todo habiendo proyectado sus rayos; éste, por su parte, adheriéndose a una esfera y acompañándola en el mismo ámbito de su movimiento, comprende la redondez en sus partes. Incluso al hombre mismo de una manera lo percibe el sentido, de otra la imaginación, de otra la razón y de otra diferente la inteligencia. En efecto, el sentido juzga la figura constituida en una materia dada; la imaginación, la sola figura sin materia. La razón, de su lado, trasciende la figura y determina, en su consideración universal, la especie que existe en los singulares. Y, por fin, el ojo de la inteligencia ocupa un lugar más excelso; pues habiendo traspasado ese ámbito del universal, intuye la misma forma simple con la pura agudeza de su mente.

En lo cual debe considerarse principalmente esto: que la facultad superior de comprehensión abraza la inferior, mas la inferior de ningún modo alcanza la superior. En efecto, ni el sentido puede algo más allá de la materia, ni la imaginación

\footnotetext{
4 PL $63,848 \mathrm{c}-850 \mathrm{~b}$.
} 
intuye las especies universales, ni la razón aprehende la forma simple, sino que la inteligencia, como si mirara desde lo alto, habiendo concebido la forma, distingue todo lo que ella subsume, y de ese modo comprende la forma misma a la cual ninguna otra facultad hubiera podido llegar a conocer. Pues ella conoce el universal de la razón, la figura de la imaginación y el material sensible, no sirviéndose de la razón ni de la imaginación ni de los sentidos, sino proviéndolo todo con aquel, por así decir, golpe formalmente único de la mente. Incluso la razón, cuando considera algo universal, comprende las imaginaciones y los datos sensibles no serviéndose de la imaginación ni de los sentidos. Ella, en efecto, es la que define el universal de su concepción asi: "el hombre es un animal bípedo racional". Esta aunque sea una noción universal, con todo nadie ignora que es una cosa imaginable y sensible, a la cual la razón considera no con la imaginación o el sentido sino con una concepción racional. Así también la imaginación, aunque tenga como punto de partida para ver y conformar las figuras los sentidos, sin embargo apartándose del sentido ilumina las cosas sensibles, no con una razón sensible sino con otra razón imaginativa de juzgar. ¿Ves, entonces, cómo, en el conocer, todas estas utilizan antes bien su propia facultad, que las cosas que son conocidas? y ello es justo, pues, ya que todo juicio es un acto del que juzga, es necesario que cada uno perfeccione su obra no a partir del poder ajeno, sino del propio. 